\title{
The Role of Bordetella Infections in Patients with Acute Exacerbation of Chronic Bronchitis
}

\author{
J. Bonhoeffer, G. Bär, M. Riffelmann, M. Solèr, U. Heininger
}

\begin{abstract}
Background: Acute exacerbations of chronic bronchitis (AECB) are associated with a variety of viral and bacterial infectious agents, some of which are potentially preventable by immunization. Bordetella pertussis, which causes whooping cough, has not been studied in this context. We aimed to assess the role of Bordetella infections in patients with AECB.

Patients and Methods: Patients with $A E C B$, who presented to participating private practices in Basel, Switzerland, between October 2000 and June 2002, were evaluated by a standardized questionnaire, nasopharyngeal swabs for culture (Bordetella spp.), and PCR (Bordetella spp. and selected other respiratory pathogens) and paired blood samples for serologic diagnosis of Bordetella infection. Results: A total of 26 patients (34-86 years of age) were recruited. All culture and PCR samples were negative. Serology revealed Bordetella infection in eight (31\%) patients. Duration of cough was shorter in patients with Bordetella infection compared to those without Bordetella infection (mean 15 days vs 41 days, $p=0.04$ ). Cough $\geq 21$ days duration was present in three $(43 \%)$ of seven patients with evidence of Bordetella infection compared to 17 (94\%) of 18 controls $(p=0.012)$. Progression to convalescence from initial to follow-up visit after 4-6 weeks was comparable between both groups.

Conclusion: Bordetella infections appear to play a significant role in $A E C B$ and preventive measurements such as immunization with acellular pertussis vaccines should be considered. Extended investigations are necessary to confirm our preliminary and provocative findings.
\end{abstract}

Infection 2005; 33: 13-17

DOI 10.1007/s15010-005-4004-9

\section{Introduction}

The mechanisms leading to acute exacerbations of chronic bronchitis (AECB) have been controversially discussed. While viral agents may initially play an important role, colonizing bacteria then proliferate and aggravate symptoms. The use of antibiotics in this context remains a topic of debate. New data indicate the importance of recently acquired strains of bacteria for the induction of AECB [1]. The potential role of Bordetella pertussis in AECB has not been studied so far.

Pertussis (or whooping cough) is caused by the gramnegative bacterium $B$. pertussis or, less commonly, Bordetella parapertussis [2]. The disease not only occurs in unimmunized children and in infants too young to be immunized but also in adolescents and adults with waning immunity $[3,4]$. Complications such as encephalopathy may affect patients at any age $[5,6]$. Although most countries have implemented pertussis component vaccines in their immunization programs for children, booster doses in adolescence are recommended only in a few countries [2]. The concept of general booster doses in adults is currently under discussion [7]. As an alternative, booster immunizations could be considered for selected adults at high risk for pertussis. The aim of the present study was to assess the role of Bordetella infections in adults with chronic bronchitis, who suffer from frequent exacerbations and therefore form a potential target group for booster immunization.

\section{Patients and Methods Study Population}

Patients with an acute exacerbation of AECB, presenting to one of 17 general practitioners or internists in Basel, Switzerland, were eligible to participate in this study. The diagnosis of chronic bronchitis was based on a history of cough with expectoration for $\geq 3$ months/year in two consecutive years [8].

Exacerbation was defined as increasing expectoration and/or change of sputum color with or without increased frequency or severity of cough and elevated body temperature $\left(\geq 38{ }^{\circ} \mathrm{C}\right)[9]$. Patients were excluded in the presence of known HIV infection,

\footnotetext{
J. Bonhoeffer, G. Bär, U. Heininger (corresponding author) University Children's Hospital Basel, P.O. Box, CH-4005 Basel, Switzerland; Phone: (+41/61) 685-6565, Fax:-6012, e-mail: Ulrich.Heininger@unibas.ch M. Riffelmann

Institute of Hygiene and Laboratory Medicine, Krefeld, Germany M. Solèr

St. Claraspital, Basel, Switzerland
}

Received: January 13, 2004 Revision accepted: May 1, 2004 
if they had received any immunoglobulins within 3 months prior to the date of inclusion or during the study period, or in case of participation in any other study. The study protocol was approved by the medical faculty's ethics committee, University of Basel, Switzerland, and was performed in accordance with good clinical practices (GCP) guidelines. Written informed consent was obtained from all patients.

\section{Clinical Information}

At three visits (initial presentation, 7-14 days and 4-6 weeks later) the severity of AECB was assessed by a standardized questionnaire including known exposition to $B$. pertussis, clinical variables of chronic bronchitis such as the date of first diagnosis, active smoking, number of pack-years (average packs/day multiplied by years of smoking), current number of cigarettes per day, number of exacerbations in the last 12 months, use of antibiotics in the last 3 months, and current medication. To assess the clinical features of the current exacerbation, increased cough, duration of cough, paroxysms, productive cough, increased expectoration, change in sputum color, whooping, post-tussive vomiting, and similar previous exacerbations were recorded. Dyspnea was assessed by the conventional performance scale in which level 1 represents the least and level 5 the most severe impact on everyday performance [10].

\section{Specimen Collection and Laboratory Procedures}

Two nasopharyngeal swabs (NPS) and a venous blood sample were taken at the initial visit and a second blood specimen was obtained at the 4-6 week follow-up visit. One NPS (in modified Regan-Lowe transport medium) was used for culture of B. pertussis or B. parapertussis in Stainer-Scholte broth and on ReganLowe agar in the microbiological laboratory of the University Children's Hospital in Basel. Conventional bacterial cultures were not performed. The second NPS (in sterile $0.9 \% \mathrm{NaCl}$ ) was used for PCR analyses, which were performed in laboratory facilities separate from those for bacterial cultures. The methods have been described in detail [11-13]. In addition, aliquots of NPS for PCR analyses were sent to the microbiological laboratory, University Children's Hospital Kiel, Germany, for single-tube multiplex reverse transcription PCR [14]. Primers for DNA sequences of $M y$ coplasma pneumoniae, Chlamydia pneumoniae, adeno-, entero-, parainfluenza type 1 , parainfluenza type 3 , influenza-A, influenza$\mathrm{B}$, and respiratory-syncytial virus were used.

Serological analyses were performed at the German National Reference Center for Bordetella Infections (Institute of Hygiene and Laboratory Medicine, Krefeld). IgG and IgA antibodies against filamentous hemagglutinin (FHA) and pertussis toxin (PT) were determined by a well-established, in-house ELISA [15, 16]. Paired sera were analyzed in the same test. An internal reference was used for constructing the reference line, where Food and Drug Administration - Center for Biologics Evaluation and Control (FDA-CBER) reference sera 3 and 4 served as controls. The minimal level of detection was $1.9-3.0 \mathrm{U} / \mathrm{ml}$ and was arbitrarily set as $2.0 \mathrm{U} / \mathrm{ml}$ for all methods. Intra-assay serology varied from $3.0 \%$ (anti-FHA $\operatorname{IgA}$ ) to $14.0 \%$ (anti-PT $\operatorname{IgA}$ ) [16, 17]. No other serological tests were performed.

\section{Case Definitions}

A diagnosis of pertussis was made in the presence of a positive bacterial culture and/or PCR and/or serological evidence of $B$. pertussis infection. Serological evidence of infection was assumed in the presence of a significant increase or decrease in at least two of the four antibody assays of which at least one had to be directed against PT (IgG and/or IgA). Alternatively, antibody concentrations above the $95^{\text {th }}$ percentile (established by use of a healthy control group) in at least two of the four assays were considered diagnostic, where at least one had to be directed against PT in an acute or convalescent serum specimen. The control group consisted of healthy unvaccinated adults, i.e. regular blood donors and military staff.

A diagnosis of parapertussis was made in the presence of a positive culture and/or a positive PCR for B. parapertussis and absence of a significant antibody response to PT.

If culture and PCR were negative and significant antibody responses were directed at FHA only, it was assumed that a recent contact to either B. pertussis or B. parapertussis was possible.

A twofold increase or decrease of antibody concentrations was considered significant. Single high antibody concentrations were defined as follows (U/ml): IgG-PT $\geq 38$, IgA-PT $\geq 12$, IgG$\mathrm{FHA} \geq 86, \operatorname{IgA}-\mathrm{FHA} \geq 42$.

\section{Statistics}

Statistical analysis was performed using SPSS 11.0.0 (SPSS Inc. 2001, Chicago, IL). Independent proportions were compared by Fisher's exact test. Student's t test was used for comparison of means. Friedman test was used for comparison of ordinal data in dependent groups. $\mathrm{P}<0.05$ was considered significant.

\section{Results}

\section{Basic Characteristics}

26 patients with 26 episodes of AECB were enrolled between October 2000 and June 2002 and 25 (96\%) of them completed follow-up. One patient was not available for the 4-6 week visit because of poor compliance. The mean age of patients was 68 years and 25 of 26 patients were 40 years of age or older (median 71, range 34-86). Mean duration of chronic bronchitis was 12 years (median 10, range 2-36) with a mean of two acute exacerbations (median 1 , range 0-5) during the last 12 months. Twelve patients (46\%) were active smokers with a mean of 35 pack-years (median 40, range 1-70). None of the patients had a history of known recent exposure to $B$. pertussis. The mean interval between onset of cough and presentation was 7 days (median 5, range -21$)$. 20 patients $(77 \%)$ recalled at least one prior similar cough episode. Eight patients $(35 \%)$ had received antibiotic treatment within the last 3 months. The mean interval between last dose of antibiotic and study enrolment was 20 days (median 21, range 1-38).

\section{Laboratory Findings}

None of the 26 NPS cultures revealed growth of $B$. pertussis or B. parapertussis. In addition, all 26 PCR samples were negative for Bordetella spp. or any other infectious agent identified by multiplex PCR. For ELISA, 25 paired serum specimens and a further single acute-phase serum specimen were available. The results are shown in table 1. As can be seen, five (19\%) episodes were classified as B. pertussis infection and for three (12\%) episodes a diagnosis of "either B. pertussis or B. parapertussis infection" was made. In all of these eight episodes, Bordetella infection was detected by elevated antibody concentrations in either the 


\begin{tabular}{|c|c|c|c|c|c|c|c|c|c|}
\hline \multirow[t]{3}{*}{ Patient } & \multicolumn{4}{|c|}{ Acute serum ${ }^{b}$} & \multicolumn{4}{|c|}{ Convalescent serum ${ }^{c}$} & \multirow{3}{*}{$\begin{array}{l}\text { Interpretation of } \\
\text { serology results }\end{array}$} \\
\hline & \multicolumn{2}{|c|}{$\mathrm{PT}^{\mathrm{a}}$} & \multicolumn{2}{|c|}{$\mathrm{FHA}^{\mathrm{a}}$} & \multicolumn{2}{|c|}{ PT } & \multicolumn{2}{|c|}{ FHA } & \\
\hline & $\mathrm{IgG}$ & $\operatorname{IgA}$ & $\mathrm{IgG}$ & $\operatorname{IgA}$ & IgG & $\operatorname{IgA}$ & $\operatorname{IgG}$ & $\operatorname{IgA}$ & \\
\hline 1 & 9 & 3 & $149^{d}$ & 135 & 12 & 6 & 243 & 115 & Pertussis or parapertussis \\
\hline 2 & 10 & $<2$ & 179 & 94 & 12 & $<2$ & 186 & 112 & Pertussis or parapertussis \\
\hline 3 & 38 & 2 & 146 & 55 & - & - & - & - & Pertussis or parapertussis \\
\hline 4 & 31 & 16 & 199 & 133 & 32 & 13 & 188 & 138 & Pertussis \\
\hline 5 & 10 & 40 & 73 & 113 & 7 & 33 & 79 & 111 & Pertussis \\
\hline 6 & 79 & 3 & 42 & 39 & 68 & 5 & 52 & 43 & Pertussis \\
\hline 7 & 371 & 90 & 118 & 607 & 288 & 38 & 124 & 571 & Pertussis \\
\hline 8 & 12 & 16 & 106 & 34 & 17 & 20 & 72 & 47 & Pertussis \\
\hline \multicolumn{10}{|c|}{$\begin{array}{l}\text { a U/ml; FHA: filamentous hemagglutinin; PT: pertussis toxin; }{ }^{b} \text { venous blood sample taken at the } \\
\text { initial presentation of the patient with cough illness; }{ }^{c} \text { venous blood sample taken } 4-6 \text { weeks af- } \\
\text { ter the initial presentation of the patient with cough illness; }{ }^{d} \text { figures in bold indicate significant } \\
\text { high concentrations }(\mathrm{U} / \mathrm{ml}) \text { : IgG-PT } \geq 38 \text {, IgA-PT } \geq 12 \text {, IgG-FHA } \geq 86 \text {, IgA-FHA } \geq 42\end{array}$} \\
\hline
\end{tabular}

1.2-3.0) vs 1.8 (CI: 1.3-2.4). There were no hospital admissions or other complications reported in any study subject.

\section{Discussion}

Here we present findings from a pilot study on the role of Bordetella infection in patients with acute exacerbations of chronic bronchitis. To our knowledge, this has not been studied before and our results indicate that Bordetella infections may play a significant role in these patients.

We found evidence of Bordetella infection in eight $(31 \%)$ of 26 AECB by demonstration of elevated antibody concentrations in acute serum specimens. In three patients the antibody pattern (i.e. response to FHA only) did not allow us to discern $B$. pertussis

acute or convalescent serum specimen, whereas a significant increase or decrease of antibody concentrations was not observed in any of the paired specimens (Table 1).

\section{Clinical Findings}

There was no significant difference between patients with or without evidence for Bordetella infection concerning age, characteristics of underlying disease and clinical presentation of the current exacerbation. However, total duration of cough (documented in 25 patients) was shorter in patients with Bordetella infection compared to those without Bordetella infection: mean 15 days (95\% CI: 7-23) vs 41 days (95\% CI: $17-64$ ), $\mathrm{p}=0.04$. Furthermore, a total duration of cough $\geq 21$ days during AECB was present in three $(43 \%)$ of seven patients with evidence of Bordetella infection compared to 17 (94\%) of 18 patients without Bordetella infection ( $\mathrm{p}=0.012$; Table 2). Interestingly, four of five patients $(80 \%)$ with a duration of cough between 7 and 21 days during AECB had Bordetella infections, whereas only three of 20 patients $(15 \%)$ with cough $>21$ days duration had evidence for Bordetella infection.

Mean values of the dyspnea performance scale decreased from visit to visit in both groups, indicating similar progression to convalescence: Bordetella infection vs no Bordetella infection: initial visit 3.0 (CI: 1.9-4.0) vs 2.5 (CI: $1.95-3.05) ; 7-14$ days 2.4 (CI: $1.4-3.4)$ vs 2.0 (CI: $1.6-2.4)$; 4-6 weeks 2.1 (CI:

\begin{tabular}{|c|c|c|}
\hline Finding & $\begin{array}{c}\text { Pertussis/parapertussis } \\
\mathrm{N} / \text { total (\%) }\end{array}$ & $\begin{array}{c}\text { Others } \\
\mathrm{N} / \text { total }(\%)\end{array}$ \\
\hline Any increased cough & $8 / 8(100)$ & $18 / 18(100)$ \\
\hline Productive & $8 / 8(100)$ & $17 / 18(94)$ \\
\hline Paroxysms & $8 / 8(100)$ & $15 / 18(83)$ \\
\hline Whooping & $3 / 8(38)$ & $3 / 18(17)$ \\
\hline Post-tussive vomiting & $1 / 8(12)$ & $6 / 18(33)$ \\
\hline Any prior similar cough & $7 / 8(87)$ & $13 / 18(72)$ \\
\hline Duration of cough $\geq 21 \mathrm{~d}$ & $3 / 7(43)^{b}$ & $17 / 18(94)^{b}$ \\
\hline Duration of paroxysms $\geq 21 \mathrm{~d}$ & $2 / 7(28)$ & 7/18 (39) \\
\hline Dyspnea & $3 / 8(38)$ & $13 / 18(72)$ \\
\hline Fever & $3 / 8(38)$ & $5 / 18(28)$ \\
\hline
\end{tabular}

from $B$. parapertussis infection. Furthermore, we cannot rule out that antibody responses against FHA were caused by cross-reaction to antigens from microorganisms other than Bordetella [18]. However, there were five patients (19\%) with a significant antibody response to PT, which is specific for $B$. pertussis infection. Interestingly, in a recent study of 155 health-care workers at a German children's hospital with regular contact to patients, $6 \%$ were found to have elevated IgG and/or IgA antibodies against PT or FHA by using the same serological methods [17]. Applying the definitions by DeMelker et al. [19] (relying on a single IgG anti-PT > $100 \mathrm{EU} / \mathrm{ml}$ ) or Birkebaek et al. [20] (relying on a single Ig Ganti-PT $>123 \mathrm{EU} / \mathrm{ml}$ ) to our data, 
only one patient would have fulfilled the serological criteria for acute $B$. pertussis infection $[19,20]$. In contrast to this and other previously published serological definitions for recent exposure to B. pertussis, which are based solely on IgG antibody analyses [19-21], our definition includes $\mathrm{IgG}$ and $\mathrm{IgA}$ antibody tests. Importantly, four of the five patients fulfilling our definition of B. pertussis infection do this based on elevated anti-PT IgA antibodies.

Also, we cannot exclude the possibility that our reference values, deriving from adults without chronic bronchitis, are different from those in patients with chronic bronchitis. Overall, however, the proportion of $B$. pertussis infections in our study is in line with the $20-25 \%$ found among otherwise healthy adults with cough illnesses [3, 22-24].

Antibody determinations in convalescent specimens demonstrated little changes compared to those in acute specimens and did not contribute to the diagnostic sensitivity. This is a plausible finding, because adults are likely to have had previous infection with B. pertussis (or B. parapertussis) and secondary immune responses cause a rapid increase in antibody concentrations [25]. Furthermore, specific $\mathrm{IgA}$ and $\mathrm{IgG}$ serum antibodies do significantly decrease again within a few months after acute infection [26]. Thus, our data confirm that a single acute serum sample probably is sufficient for serological diagnosis of pertussis in adults.

It is not surprising that direct demonstration of Bordetella spp. by PCR or culture was not possible in any of the eight Bordetella infections in this study. In a recent study from Canada, 442 adolescents and adults $>12$ years of age with cough of 7-56 days duration were evaluated. Only four $(0.9 \%)$ of them were positive for $B$. pertussis by culture or PCR, whereas $84(19.1 \%)$ had serologically diagnosed B. pertussis infection [27]. This means that $B$. pertussis was detected in only one of 20 patients with pertussis. Also, in other previous investigations on pertussis in adults, $21-65 \%$ of serologically diagnosed Bordetella infections were associated with positive PCR and/or culture [28-32]. This considerable variability in direct demonstration of the organism from nasopharyngeal specimens may be due to inhomogeneous sampling techniques among different investigators, which may also have contributed to the negative finding in our study.

Thus, our data confirm that serological analysis is of paramount importance for diagnosis of pertussis not only in otherwise healthy adults, but also in those with AECB, whereas culture and PCR lack sensitivity.

To our surprise, patients with Bordetella infection had a shorter duration of cough compared to those with cough of unknown etiology. This is a new and provocative finding. It can be explained by the fact that illness caused by $B$. pertussis in adults is usually due to reinfection, which seems to occur frequently in otherwise healthy adults $[4,33]$. Our findings indicate that this is probably also the case in patients with chronic bronchitis. We offer the hypothesis that partial immunity acquired from prior infection with $B$. pertussis leads to comparatively mild symptoms during rein- fections. The atypical presentation of Bordetella infections under these circumstances makes specific microbiological investigations necessary to establish the diagnosis. This is of clinical relevance, because (1) treatment with macrolides should be initiated to avoid transmission to other susceptible individuals, especially young infants [34], and (2) no further diagnostic procedures are usually necessary.

The overall similar clinical presentation of AECB associated with Bordetella infection compared to nonBordetella infection in our study is of no surprise and has also been observed in patients without underlying pulmonary disease $[24,35,36]$. However, given the frequency of cough exacerbations in patients with chronic bronchitis, our finding of Bordetella infection in up to $30 \%$ of these episodes is relevant. In light of these data, pertussis immunization could significantly decrease the morbidity of patients with chronic bronchitis. Acellular pertussis vaccines, with proven excellent immunogenicity and safety in adolescents and adults, would be available for this purpose $[2,37]$.

Our study has limitations. Most importantly, despite our repeated efforts to remind participating physicians of the purpose and goal of this study, recruitment of patients with AECB was lower than expected. Obviously, tight schedules in their offices caused prolonged intervals of enrollment inactivity. One could argue that therefore our study sample might be biased towards recruiting patients with suspected pertussis. However, based on the unspecific clinical findings in our patients and the fact that exposure to $B$. pertussis was denied by all patients, we believe there is no indication for such a bias.

Therefore, this present study should be considered as a pilot project which provides preliminary and provocative evidence on the role of Bordetella infection in adults with acute exacerbations of chronic bronchitis. Confirmative, extended investigations are necessary.

\section{Acknowledgments}

We gratefully acknowledge the contributions to patient recruitment and data collection in the study centers by: Drs. P. Affolter, K. Bally, U. Berner, C. Kopp., S. Kradolfer, P. Ruff, A. Schlumpf, J. Leuppi, P. Tschudi, H. Wacker, C. Weber. We also acknowledge the kind performance of multiplex PCR by Dr. W. Puppe and Prof. H. J. Schmitt, microbiological laboratory, University Children's Hospital Kiel, Germany. A research grant for this study was received from GlaxoSmithKline, Münchenbuchsee, Switzerland and GlaxoSmithKline Rixensart, Belgium.

\section{References}

1. Sethi S, Evans N, Grant B, Murphy T: New strains of bacteria and exacerbations of chronic obstructive pulmonary disease. $\mathrm{N}$ Engl J Med 2002; 347: 465-471.

2. Heininger $U$ : Recent progress in clinical and basic pertussis research. Eur J Pediatr 2001; 160: 203-213.

3. Schmitt-Grohé S, Cherry, JD, Heininger U, Überall MA, Pineda E, Stehr K: Pertussis in German adults. Clin Infect Dis 1995; 21: 860-866. 
4. Deville JG, Cherry JD, Christenson PD, Pineda E, Leach CT, Kuhls TL, Viker S: Frequency of unrecognized Bordetella pertussis infections in adults. Clin Infect Dis 1995; 21: 639-642.

5. Halperin SA, Marrie TJ: Pertussis encephalopathy in an adult: case report and review. Rev Infect Dis 1991; 13: 1043-1047.

6. Heininger U, Klich K, Stehr K, Cherry JD: Clinical findings in Bordetella pertussis infections: results of a prospective multicenter surveillance study. Pediatrics 1997; http://www.pediatrics.org/ cgi/content/full/100/6/e10.

7. Edwards KM: Is pertussis a frequent cause of cough in adolescents and adults? Should routine pertussis immunisation be recommended? Clin Infect Dis 2001; 32: 1698-1699.

8. Anthonisen NR, Manfreda J, Warren CPW, Hershfield ES, Harding GKM, Nelson NA: Antibiotic therapy in exacerbations of chronic obstructive pulmonary disease. Ann Intern Med 1987; 106: 196204.

9. Ingram RH: Chronic bronchitis, emphysema, and airways obstruction. In: Isselbacher KJ, Braunwald E, Wilson JD, Martin JB (eds): Harrison's principles of internal medicine (13 $3^{\text {th }}$ edn). Mc Graw Hill, New York 1994, pp 1197-1206.

10. American Thoracic Society: Surveillance for respiratory hazards in the occupational setting. Am Rev Respir Dis 1982; 126: 952956.

11. Heininger U, Cherry JD, Eckhardt T, Lorenz C, Christenson P, Stehr $\mathrm{K}$ : Clinical and laboratory diagnosis of pertussis in the regions of a large vaccine efficacy trial in Germany. Pediatr Infect Dis J 1993; 12: 504-509.

12. Heininger U, Stehr K, Schmitt-Grohé S, Lorenz C, Rost R, Christenson P, Überall $M$, Cherry JD: Clinical characteristics of illness caused by Bordetella parapertussis compared with illness caused by Bordetella pertussis. Pediatr Infect Dis J 1994; 13: 306-309.

13. Schläpfer G, Senn HP, Berger R, Just M: Use of the polymerase chain reaction to detect Bordetella pertussis in patients with mild or atypical symptoms of infection. Eur J Clin Microbiol Infect Dis 1993; 12: 459-463.

14. Grondahl B, Puppe W, Hoppe A, Kuhne I, Weigl JA, Schmitt HJ: Rapid identification of nine microorganisms causing acute respiratory tract infections by single-tube multiplex reverse transcription-PCR: feasibility study. J Clin Microbiol 1999; 37: 1-7.

15. Müller FM, Hoppe JE, Wirsing von König CH: Laboratory diagnosis of pertussis: state of the art in 1997. J Clin Microbiol 1997; 35: 2435-2443.

16. Wirsing von König $\mathrm{CH}$, Schmitt $\mathrm{HJ}$ : Epidemiologic aspects and diagnostic criteria for a protective efficacy field trial of a pertussis vaccine. J Infect Dis 1996; 174 (Suppl.): 281-286.

17. Riffelmann M, Koesters K, Saemann-Ischenko G, Schmitt HJ, Wirsing von Koenig $\mathrm{CH}$ : Antibodies to pertussis antigens in pediatric health care workers. Pediatr Infect Dis J 2002; 21: 381-383.

18. Vincent JM, Cherry JD, Nauschuetz WF, Lipton A, Ono CM, Costello CN, Sakaguchi LK, Hsue G, Jackson LA, Tachdjian R, Cotter PA, Gornbein JA: Prolonged afebrile nonproductive cough illnesses in American soldiers in Korea: a serological search for causation. Clin Infect Dis 2000; 30: 534-539.

19. De Melker HE, Versteegh FGA, Conyn-van Spaendonck MAE, EIvers LH, Berbers GAM, van der Zee A, Schellekens JFP: Specificity and sensitivity of high levels of immunoglobulin $G$ antibodies against pertussis toxin in a single serum sample for diagnosis of infection with Bordetella pertussis. J Clin Microbiol 2000; 38 : $800-806$.

20. Birkebaek NH, Kristiansen M, Seefeldt T, Degn J, Moller A, Heron I, Andersen PL, Moller JK, Ostergard L : Bordetella pertussis and chronic cough in adults. Clin Infect Dis 1999; 29: 1239-1242.
21. Yih WK, Lett SM, des Vignes FN, Garrison KM, Sipe PL, Marchant CD: The increasing incidence of pertussis in Massachusetts adolescents and adults, 1989-1998. J Infect Dis 2000; 182: 14091416.

22. Robertson PW, Goldberg H, Jarvie BH, Smith DD, Ross Whybin L: Bordetella pertussis infection: a cause of persistent cough in adults. Med J Aust 1987; 146: 522-525.

23. Nennig ME, Shinefield HR, Edwards KM, Black SB, Fireman BH: Prevalence and incidence of adult pertussis in an urban population. JAMA 1996; 275: 1672-1674.

24. Mink C, Cherry J, Christenson P, Lewis K, Pineda E, Shlian D, Dawson J, Blumberg D: A search for Bordetella pertussis infection in university students. Clin Infect Dis 1992; 14: 464-471.

25. Stehr K, Lugauer S, Heininger U, Uhlenbusch R, Cherry JD: Verträglichkeit und Immunogenität der Keuchhustenimpfung mit einem azellulären monovalenten 4-Komponenten-Impfstoff (Lederle/Takeda) bei 185 Erwachsenen. Pädiatr Grenzgeb 1995; 34: 219-223.

26. Heininger U, Cherry JD, Stehr K: Serologic response and antibody-titer decay in adults with pertussis. Clin Infect Dis 2004; 38: 591-594.

27. Senzilet LD, Halperin SY, Spika JS, Alagaratnam M, Morris A, Smith B, Sentinel Health Unit Surveillance System Pertussis Working Group: Pertussis is a frequent cause of prolonged cough illness in adults and adolescents. Clin Infect Dis 2001; 32: 1691-1697.

28. Heininger U, Schmitt-Schläpfer G, Cherry JD, Stehr K: Clinical validation of a polymerase chain reaction assay for the diagnosis of pertussis by comparison with serology, culture, and symptoms during a large pertussis vaccine efficacy trial. Pediatrics 2000; http://www.pediatrics.org/cgi/content/full/105/3/e31.

29. Li ZM, Jansen DL, Finn TM, Halperin SA, Kasina A, O'Connor SP, Aoyama T, Manclark CR, Brennan MJ: Identification of Bordetella pertussis infection by shared-primer PCR. J Clin Microbiol 1994; 32: $783-789$.

30. Lind-Brandberg L, Welinder-Olsson C, Lagergard T, Taranger J, Trollfors B, Zackrisson G: Evaluation of PCR for diagnosis of Bordetella pertussis and Bordetella parapertussis infections. J Clin Microbiol 1998; 36: 679-683.

31. Reizenstein E, Lindberg L, Möllby R, Hallander HO: Validation of nested Bordetella PCR in a pertussis vaccine trial. J Clin Microbiol 1996; 34: 810-815.

32. Van der Zee A, Agterberg C, Peeters M, Mooi F, Schellekens J: A clinical validation of Bordetella pertussis and Bordetella parapertussis polymerase chain reaction: Comparison with culture and serology using samples from patients with suspected whooping cough from a highly immunized population. J Infect Dis 1996; 74: 89-96.

33. Versteegh FG, Schellekens JF, Nagelkerke AF, Roord JJ: Laboratory-confirmed reinfections with Bordetella pertussis. Acta Paediatr 2002; 91: 95-97.

34. Nelson JD: The changing epidemiology of pertussis in young infants: the role of adults as reservoirs of infection. Am J Dis Child 1978; 132: 371-373.

35. Wirsing von König $\mathrm{CH}$, Tacken A, Finger $\mathrm{H}$ : Keuchhusten bei Erwachsenen. Dtsch Med Wochenschr 1991; 116: 649-653.

36. Rosenthal S, Strebel P, Cassiday P: Pertussis Infection among adults during the 1993 outbreak in Chicago. J Infect Dis 1995; 171: 1650-1652.

37. Keitel WA: Cellular and acellular pertussis vaccines in adults. Clin Infect Dis 1999; 28 (Suppl. 2): 118-123. 